\title{
O valor-trabalho como fundamento dos preços ${ }^{1}$
}

\author{
Cláudio Gontijo ${ }^{2}$
}

\section{Resumo}

Este artigo procura demonstrar que a lei do valor possui caráter axiomático e representa fundamento necessário do sistema de preços de produção. Abandoná-la significa romper com o princípio da autofundamentação da ciência, formulado em $O$ Capital, abrir mão do princípio unificador da economia clássica em favor de teorias baseadas em hipóteses graciosas e renunciar a uma teoria geral das economias de mercado. A proposta neorricardiana de se derivar a taxa de lucro e os preços diretamente dos "coeficientes técnicos de produção" e do salário real omite a duração da jornada e a intensidade do trabalho, escamoteando o conteúdo social dessas variáveis.

Palavras-chave: Economia marxista; Valor (Economia); Distribuição (Teoria econômica); Teoria trabalhista do valor.

\begin{abstract}
The law of value as the foundation of the prices

This article shows that the law of value is axiomatic and constitutes the necessary foundation of the prices of production. Giving up this foundation means to break with the self-found principle of science, to abandon the unifying principle of classical economics in favor of unsystematic theories based on ad hoc hypotheses and to give up on a general theory of market economies. The neoRicardian proposal to determine prices and the profit rate directly from "technical coefficients" and the real wage omits the length of the working-day and the intensity of the labor process, concealing the sociologic contents of those variables.
\end{abstract}

Key words: Marxian economics; Standard of value; Value and distribution; Theory of value. JEL B51.

\section{Introdução}

Desde a publicação do Livro III de $O$ Capital que a questão da transformação de valores em preços tem sido um tema recorrente e controverso na economia marxista. Concebida como uma crítica definitiva à teoria de preços da "economia vulgar" (Engels, 1894), a construção marxista tornou-se ela mesma objeto de ataques acerbos, centrados na aparente impossibilidade de se preservar o "lema de Marx." (Monza, 1979), que estabelece a identidade simultânea entre as somas dos valores e dos preços de produção e entre as massas de mais-valia e de lucros. De tosquiador a tosquiado, o marxismo aparentemente se fragmentou na tentativa de dar uma resposta adequada ao problema, com a proliferação de

(1) Trabalho recebido em dezembro de 2007 e aprovado em junho de 2008.

(2) Professor Adjunto da Faculdade de Ciências Econômicas da Universidade Federal de Minas Gerais (UFMG), Belo Horizonte, MG, Brasil. E-mail: claudio.gontijo@ fead.br. 
"soluções" que, além de incompatíveis entre si, aparentemente requerem a reformulação radical de conceitos fundamentais desenvolvidos em $O$ Capital. $^{3}$

Este artigo procura resgatar a abordagem marxista original, que apresenta a lei do valor como o fundamento dos preços de produção, concebidos como centros de gravitação dos preços de mercado. Nessa perspectiva, a questão da transformação - tal como colocada por inúmeros autores - surge como um falso problema, originado da incompreensão da natureza e dos limites do erro de Marx., o que de modo algum invalida a sua brilhante formulação. Não se tenta, contudo, uma "releitura" inovadora de $O$ Capital, assim como não se procede a qualquer desenvolvimento analítico novo. Pelo contrário, procura-se, utilizando-se de material conhecido, realizar uma reflexão sobre o assunto que, apesar de modesta, pode lançar alguma luz sobre terreno tão inóspito. Por se tratar de questão específica e complexa, cuja discussão demandaria todo um paper, não se examina, aqui, a questão da epistemologia da transformação. Finalmente, de forma a não sobrecarregar o texto com outras questões, supôs-se uma economia sem produção conjunta.

Este artigo desdobra-se em três seções, além desta introdução. Na seção 1, apresenta-se a questão da transformação de valores em preços de produção em Marx, ressaltando-se os problemas envolvidos na formalização marxista que invalidam o "lema de Marx". Na seção 2, demonstra-se como se pode, a partir da lei do valor, determinar a taxa de lucro e, portanto, os preços de produção. A questão da necessidade da lei do valor no processo de determinação desses preços é discutida na seção 3. O sumário e as conclusões encontram-se na última seção. De forma a facilitar a leitura deste texto por estudantes de economia, as citações foram traduzidas pelo autor.

\section{A transformação de valores em preços de produção em Marx e a crítica de Samuelson-Steedman-Napoleoni}

A questão da transformação de valores em preços de produção ganha inteligibilidade quando se concebe $O$ Capital como a exposição científica (Darstellung) da teoria axiomática da economia mercantil generalizada, cujo ponto de partida é a mercadoria, concebida como universal concreto - forma que resume, de modo não desenvolvido, as determinações e relações da totalidade desenvolvida (o Capitalismo). ${ }^{4}$ Acompanhando a lógica imanente do

(3) Para uma avaliação crítica da "nova solução" do problema da transformação de valores em preços, ver Sinha (1997); Fine, Lapavitsas e Saad-Filho (2004); Ravagnani (2005) e Gontijo (2006). Uma apreciação crítica do enfoque do "sistema temporal único" encontra-se em Mongiovi (2002) e Gontijo (2005).

(4) "A riqueza das sociedades onde rege a produção capitalista configura-se em "imensa acumulação de mercadorias", e a mercadoria, isoladamente considerada, é a forma elementar dessa riqueza" (Marx, 1893, livro I, cap. I, p. 41). 
desdobramento das determinações da mercadoria, Marx mostra, nos Capítulos I e II de $O$ Capital, como o processo de troca faz exteriorizar a diferença entre valor de uso e valor de troca como oposição entre mercadoria e dinheiro. No capítulo III, demonstra como a própria circulação mercantil provoca a inversão dos seus termos, gerando espontaneamente o processo de acumulação indefinida de mais dinheiro, que, assim, se transforma em capital-dinheiro cuja finalidade é gerar mais dinheiro.

Esse processo de acumulação de capital, contudo, não é autossustentado, pois depende do contínuo lançamento à circulação de mercadorias que, todavia, não são produzidas de forma capitalista, não são "produtos do capital", e da retirada da mercadoria dinheiro da circulação, na forma de entesouramento. Para que o capital se transforme em sujeito do processo, ou seja, para que ponha seus próprios pressupostos, de modo a se ter um processo autossustentado, é necessário que a força de trabalho seja mercadoria, pois somente neste caso fecha-se o ciclo, com o processo de produção de mercadorias se transformando em processo de valorização do capital. É claro que a existência da força de trabalho como mercadoria não depende exclusivamente da lógica imanente da própria mercadoria, visto que, originariamente, o trabalhador é proprietário de seus meios de produção, tratando a natureza como a extensão objetiva de sua subjetividade (Marx, 1975, p. 93). Há de se supor, portanto, a ocorrência de um processo histórico anterior que tenha despojado os trabalhadores dos meios de produção, que, assim, estarão concentrados nas mãos de outra classe social - a classe capitalista (Marx, 1863, livro I, cap. IV, p. 187-197).

Uma vez tendo explicado como o dinheiro se transforma em capital "à base das leis imanentes da troca de mercadorias", de modo que "a troca de equivalentes [ou seja, a lei do valor] serve de ponto de partida" (Marx, 1863, livro I, cap. IV, p. 185), Marx passa, nos capítulos seguintes do Livro I de $O$ Capital, a mostrar como, ainda com base na mesma teoria do valor-trabalho, se resolve a aparente contradição entre a geração de mais-valia e a troca de equivalentes; como se dá a conversão do valor da força de trabalho em salário (capital variável); e como ocorre a acumulação capitalista. Somente depois de examinar (Livro II de $O$ Capital), ainda com base na lei do valor, as conexões entre a circulação do capital e a circulação mercantil que garantem as condições de reprodução da sociedade capitalista, é que Marx se defronta, no Livro III de $O$ Capital, com a tarefa de demonstrar como a mais-valia se transforma em lucro, o capital variável em salário e os valores em preços de produção. Tal demonstração equivale, portanto, a descortinar a maneira pela qual a lei do valor governa os preços de produção, 
concebidos, conforme salientado, como centros de gravitação dos chamados preços de mercado, que configuram a "realidade efetiva" (Wirklichkeit). ${ }^{5}$

Para Marx (1894, Livro III, Cap. X, p. 196-197), o processo de transformação resulta da concorrência entre capitais, que

...reparte o capital da sociedade entre os diferentes ramos de produção, de maneira tal que os preços de produção em cada ramo se constituem segundo o modelo dos preços de produção nos ramos de composição média ... Essa taxa média de lucro nada mais é do que o lucro percentualmente calculado nos ramos de composição média, em que o lucro coincide, portanto, com a mais-valia. A taxa de lucro é assim a mesma em todos os ramos, sendo portanto nivelada por aquela dos ramos médios, em que domina a composição média do capital.

\section{Como consequência,}

...a soma dos lucros de todos os ramos de produção deve ser igual à soma das maisvalias, e a soma dos preços de produção da totalidade do produto social, igual à soma dos valores (Marx, 1894, livro III, cap. X, p. 197), de modo que os desvios de preços reciprocamente se anulam com a repartição uniforme da mais-valia, ou então com o acréscimo do lucro médio (...) aos preços de custo das mercadorias (...). Uma mercadoria se vende acima do valor na mesma medida em que a outra é vendida abaixo (Marx, 1894, livro III, cap. X, p. 178-179).

De forma a examinar formalmente o processo de transformação proposto por Marx, suponha uma economia simples, sem capital fixo ou produção conjunta, onde os salários participam do capital imobilizado e a terra não paga aluguel. Nessas condições, o vetor-linha das quantidades de trabalho social direto e indireto gasto na produção de cada uma das mercadorias, $\phi$, pode ser expresso por:

$$
\phi=\phi \mathbf{A}+\mathbf{a}_{0}
$$

onde A significa a matriz de coeficientes técnicos de produção, de modo que $\boldsymbol{\phi} \mathbf{A}$ representa a quantidade de trabalho total alocado na produção dos insumos e $\mathbf{a}_{0}$ é o vetor de coeficientes de trabalho. Assumindo-se, então, que o sistema econômico produza um excedente sobre o consumo de insumos, ${ }^{6}$ conclui-se que a quantidade de trabalho socialmente necessário para a produção das mercadorias está dada por:

(5) Conforme salienta Marx (1894, livro III, cap. I, p. 30), com esse passo adicional as configurações do modo de produção capitalista "abeiram-se gradualmente da forma em que aparecem na superfície da sociedade, na interação dos diversos capitais, na concorrência e ainda na consciência normal dos próprios agentes da produção".

(6) A produtividade do sistema econômico significa que, em pelo menos um setor, a produção é maior do que o consumo de insumos necessários para viabilizá-la. Formalmente, tem-se que:

$\mathbf{x} \geq \mathbf{A} \mathbf{x}$,

onde $\mathbf{x}$ representa o vetor coluna das quantidades produzidas e o símbolo $\geq$ significa que prevalece a desigualdade em pelo menos um caso. Uma vez que, por construção, a soma das colunas da matriz $\mathbf{A}$ é menor do que a unidade, prova-se que a matriz [I-A] é de Mayakovsky, de forma que tem inversa e é não negativa (ou seja, as condições de Hawk-Simons são satisfeitas). Ver Graham (1987). 


$$
\phi=\mathbf{a}_{0}+\mathbf{a}_{0} \mathbf{A}+\mathbf{a}_{0} \mathbf{A}^{2}+\mathbf{a}_{0} \mathbf{A}^{3}+\ldots=\mathbf{a}_{\mathbf{0}}[\mathbf{I}-\mathbf{A}]^{-1}
$$

onde $[\mathbf{I}-\mathbf{A}]^{-1}$ é a matriz inversa de Leontief, $\mathbf{a}_{\mathbf{0}} \mathbf{A}$ significa a quantidade de trabalho social gasto na produção dos insumos, $\mathbf{a}_{0} \mathbf{A}^{2}$ representa a quantidade de trabalho social gasto na produção dos insumos e assim sucessivamente.

Ressalte-se, por outro lado, que não há produção mercantil sem dinheiro, na medida em que "o desenvolvimento histórico da troca desdobra a oposição latente na natureza das mercadorias, entre valor-de-uso e valor", de forma que "os produtos de trabalho se convertem em mercadorias no mesmo ritmo em que determinada mercadoria se transforma em dinheiro" (Marx, 1867, livro I, cap. II, p. 97).

Considerando-se, então, que o dinheiro representa a mercadoria historicamente escolhida como equivalente geral (Marx, 1867, livro I, cap. II, p. 97-100), ${ }^{7}$ conclui-se que, tomando-se $\phi_{0}$ como a quantidade de trabalho social despendido na produção de determinada quantidade (libra) da mercadoria-dinheiro (ouro), concebida como unidade de medida valor, ${ }^{8}$ o vetor-linha que expressa monetariamente as quantidades de trabalho social, ou seja, o vetor dos valores, $\mathbf{v},{ }^{9}$ ou valores de troca, será dado por:

$$
\mathbf{v}=\boldsymbol{\phi} / \phi_{0}=\mathbf{a}_{\mathbf{0}}[\mathbf{I}-\mathbf{A}]^{-1} / \phi_{0}
$$

o que significa que o valor de uma libra de ouro, $v_{\text {ouro, }}$ em termos do próprio padrão de valor, será tautologicamente unitário. ${ }^{10}$

$$
\mathrm{v}_{\text {ouro }}=1
$$

A identidade (3) é importante, pois mostra claramente que os valores dependem apenas da quantidade de trabalho social - que, por sua vez, é função da tecnologia de produção cristalizada nos "coeficientes técnicos" do vetor $\mathbf{a}_{0}$ e da matriz $\mathbf{A}$-, de modo que independem da distribuição de renda. Isso significa que, embora seja o ponto de partida do estudo de qualquer sociedade mercantil, a

(7) Em outras palavras, o dinheiro é a mercadoria que expressa o tempo de trabalho social gasto em todas as outras mercadorias.

(8) "Para fazer do ouro estalão dos preços, determinado peso dele tem de ser eleito unidade de medida" (Marx, 1867, livro I, cap. III, p. 110)

(9) "Os preços, ou as quantidades de ouro em que se transformam, idealmente, os valores das mercadorias, são agora expressos nos nomes de moedas, ou seja, nos nomes legalmente válidos do padrão-ouro" (Marx, 1867, livro I, cap. III, p. 112). "A expressão simples e relativa do valor de uma mercadoria (...) através de uma mercadoria que já esteja exercendo a função de mercadoria-dinheiro, por exemplo, o ouro, é a forma preço" (Marx, 1867, livro I, cap. I, p. 79), entendendo-se por preço, aqui, o valor, ou seja, a "designação do trabalho corporificado na mercadoria" (Marx, 1867, livro I, cap. III, p. 114).

(10) Obviamente que "o dinheiro (...) não tem preço. Para participar dessa forma unitária do valor relativo das outras mercadorias, teria de referir-se a si próprio, como o equivalente de si mesmo" (Marx, 1867, livro I, cap. III, p. 106). 
equação (3) é insuficiente para se examinar a anatomia da sociedade capitalista, onde a renda gerada pelo processo produtivo, definida como a diferença entre a produção e o consumo produtivo de meios de produção, é apropriada não apenas pelos trabalhadores, mas também pelos proprietários dos meios de produção - os capitalistas.

Reconhecendo, então, que, como todas as outras mercadorias, o valor da mercadoria força de trabalho deve ser igual ao seu custo de reprodução, Marx postula que o salário, em termos de valor, $\omega$, deve ser igual ao valor da cesta de bens e serviços necessários à reprodução da força de trabalho $(\mathbf{d})$, de modo que se tem:

$$
\omega=\mathbf{v} \mathbf{d}
$$

o que permite demonstrar que, conforme supõe Marx (MARX, 1894, Livro III , Cap. VIII, p. 161-162), a taxa de mais-valia, $\varepsilon$, é única em toda a economia. De fato, considerando-se que a mais-valia é a diferença entre o valor da mercadoria e a soma do consumo de insumos com o valor da força de trabalho utilizada na produção do mesmo, obtém-se o seguinte sistema de equações homogêneas:

$$
\mathbf{v}=\boldsymbol{v} \mathbf{A}+\boldsymbol{v} \mathbf{d} \mathbf{a}_{\mathbf{0}}+\boldsymbol{\mu}=\boldsymbol{v} \mathbf{A}+(1+\varepsilon) \boldsymbol{v d} \mathbf{a}_{\mathbf{0}}
$$

onde $\mathbf{v} \mathbf{d} \mathbf{a}_{\mathbf{0}}$ retrata o montante do capital variável por unidade de produto em cada setor e $\mu$ é o vetor dos montantes de mais-valia por unidade do produto.

De (3), (5) e (6) obtém-se a taxa de mais-valia como a relação entre o trabalho excedente $(1-\boldsymbol{\phi} \mathbf{d})$ e o trabalho necessário $\boldsymbol{\phi} \mathbf{d}$ (ou seja, a quantidade de trabalho requerida para a produção dos meios de reprodução da força de trabalho):

$$
\varepsilon=(1-\phi \mathbf{d}) / \phi \mathbf{d}
$$

o que, de mais a mais, confirma a suposição marxista a respeito da unicidade da taxa de mais-valia (Marx, 1894, livro III , cap. ỴIII, p.161-162).

Define-se, por outro lado, os preços de produção, $\mathbf{p}$, como aquelas razões de troca que permitem aos capitais aplicados nos diferentes setores da economia obter a mesma taxa de lucro, $r$, de modo que se tem:

$$
\mathbf{p}=\mathbf{p} \mathbf{A}+\mathrm{w} \mathbf{a}_{\mathbf{0}}+\mathrm{r}\left(\mathbf{p} \mathbf{A}+\mathrm{w} \mathbf{a}_{\mathbf{0}}\right)=(1+\mathrm{r})\left(\mathbf{p} \mathbf{A}+\mathrm{w} \mathbf{a}_{\mathbf{0}}\right)
$$

onde $\mathbf{p}$ A representa o vetor dos custos de insumos, w $\mathbf{a}_{0}$ é o vetor dos custos de mão de obra e r (p A + w $\mathbf{a}_{0}$ ) significa o vetor dos lucros "normais" unitários, ou seja, dos lucros que correspondem à taxa média de lucro. 
Assumindo-se, então, apenas para efeitos de simplificação, que a cesta de reprodução da classe trabalhadora é invariável em relação aos preços relativos, ${ }^{11}$ pode-se definir, por simetria, no sistema de preços acima, o salário nominal como o valor monetário da cesta de consumo dos trabalhadores:

$$
\mathrm{W}=\mathbf{p} \mathbf{d}
$$

fixando-se, então, a mesma quantidade da mercadoria-dinheiro (ouro) que foi utilizada como unidade de medida no sistema de valores como unidade de medida dos preços, de forma que o preço dessa mesma quantidade é obviamente unitário $^{12}$ :

$$
\mathrm{p}_{\text {ouro }}=1
$$

obtém-se o sistema de preços de produção, agora expressos em quantidades da mercadoria-dinheiro, dado por:

$$
\mathbf{p}=(1+\mathrm{r}) \mathbf{p}\left(\mathbf{A}+\mathbf{d} \mathbf{a}_{\mathbf{0}}\right)
$$

A tese marxista consiste em sustentar que, uma vez que a taxa de lucro $r$ é determinada no sistema de valores, como igual ao quociente $b$ entre o montante da mais-valia ( $\left.\varepsilon \boldsymbol{v} \mathbf{d} \mathbf{a}_{\mathbf{0}} \mathbf{x}\right)$ e o total do valor do capital ( $\left.\boldsymbol{v} \mathbf{A}+\boldsymbol{v} \mathbf{d} \mathbf{a}_{\mathbf{0}}\right)$, de forma que se tem:

$$
r=b=\varepsilon v d a_{0} \mathbf{x} / \mathbf{v}\left(A+d a_{0}\right) \mathbf{x}
$$

onde $\mathbf{x}$ significa o vetor coluna de quantidades produzidas, o valor da produção total é o mesmo, quer seja expresso em termos de valor-trabalho, quer seja valorado em preços de produção:

$$
\mathbf{v} \mathbf{x}=\mathbf{p} \mathbf{x}
$$

o mesmo ocorrendo com o total da mais-valia, que se iguala, assim, ao montante dos lucros:

$$
\varepsilon v \mathbf{d} \mathbf{a}_{0} \mathbf{x}=\operatorname{r} \mathbf{p}\left(\mathbf{A}+\mathbf{d} \mathbf{a}_{\mathbf{0}}\right) \mathbf{x}
$$

(11) Pode-se argumentar, com razão, que essa hipótese é irrealista, pois supõe que, diante da elevação de preços de determinados produtos que compõem a sua cesta de reprodução, os trabalhadores não os substituam por outros similares mais baratos. Contudo, o tratamento do "efeito substituição" - caro à teoria neoclássica - além de teoricamente incerto dentro do marxismo - complicaria demasiadamente a discussão sem propiciar ganhos aparentes. Por outro lado, pode-se concordar com Tavares (1978, p. 54), que o conceito de "consumo necessário dos trabalhadores" está cada vez mais afastado da noção de "tempo socialmente necessário para a subsistência da força de trabalho". Não somente porque a cesta de reprodução da classe trabalhadora difere do tempo de trabalho social gasto em produzi-la, mas em razão da própria diferença entre valor e preço de produção e entre valor e tempo de trabalho, sua substância. Também Belluzzo (1980, p. 110) vê como equívoca a "identificação entre valor da força de trabalho e 'cesta' fixa de bens-salário".

(12) A fixação do preço de produção de uma libra de ouro como unitário decorre da hipótese adotada por Marx de que o ouro representa a moeda-mercadoria tanto no sistema de valores quanto de preços e que a mesma unidade de medida (peso) é utilizada no estabelecimento do padrão de preços em ambos os sistemas. 
Examinando-se, contudo, as identidades (8), (9) e (10), não é difícil de se perceber a inconsistência da proposta marxista, uma vez que, para começar, o sistema de equações por elas constituído é suficiente para determinar tanto a taxa de lucro quanto os preços, inclusive o da força de trabalho. De fato, resolvendo-se a seguinte equação característica:

$$
\operatorname{det}\left[\rho \mathrm{I}-\left(\mathbf{A}+\mathbf{d} \mathbf{a}_{\mathbf{0}}\right)\right]=0
$$

obtida a partir da identidade (9), determina-se a taxa de lucro do sistema de preços, dada por:

$$
\mathrm{r}=1 / \rho_{\mathrm{MAX}}-1
$$

Substituindo-se, então, r em (10), obtém-se o vetor de preços de produção p, o que, por sua vez, permite determinar o salário nominal através da identidade (8). Devemos destacar que, em geral, não prevalecem as identidades (11), (12) e (13), de modo que, conforme salientado por Samuelson (1971 e 1974), Napoleoni (1977) e Steedman (1977), não só a taxa de lucro e o vetor de preços de produção são determinados independentemente do sistema de valores. ${ }^{13}$ Além disso, a taxa de lucro $r$ difere do quociente entre o total da mais-valia e o valor total do capital, a soma dos valores não é igual à soma dos preços, nem o total da mais-valia é igual ao montante dos lucros. ${ }^{14}$

De forma a tornar o assunto mais claro, considere-se uma economia hipotética, que produz apenas cinco mercadorias, e que as mercadorias (oriundas dos setores I e II) são exclusivamente meios de produção; o setor III produz a mercadoria-dinheiro (ouro); o setor IV produz meios de subsistência e o setor V bens de luxo (que, por definição, não são insumos de nenhuma outra mercadoria, correspondendo, pois, à definição sraffiana de "mercadoria não básica").

Para efeitos de simplificação, supõe-se um sistema sem capital fixo e que o período de rotação do capital circulante seja unitário. O Quadro 1 traz os coeficientes técnicos de produção, inclusive os coeficientes de trabalho (em termos de quantidade média de trabalho executada por uma pessoa por um ano e por unidade de produto) que, também para efeito de simplificação, são considerados constantes. Assumindo-se, então, dada acesta de reprodução da família operária (que, no exemplo considerado, é composta de 10 unidades produzidas pelo setor III), pode-se determinar tanto os valores quanto os preços das cinco mercadorias.

(13) Erra Napoleoni (1977, p. 96), contudo, quando afirma que "as quantidades de trabalho não têm qualquer importância na determinação dos preços e da taxa de lucro", pois, conforme mostram as identidades (10) e (14), sem os coeficientes de trabalho não se determinam essas variáveis.

(14) Conforme salienta Tavares (1978, p. 47), "a possibilidade de equivalência entre lucro e mais-valia requer condições altamente restritivas". 
Quadro 1

Coeficientes técnicos de produção

\begin{tabular}{|l|c|c|c|c|c|}
\hline Setores & Setor I & Setor II & Setor III & Setor IV & Setor V \\
\hline Setor I & 0,10 & 0,05 & 0,02 & 0,05 & 0,02 \\
\hline Setor II & 0,20 & 0,04 & 0,10 & 0,02 & 0,01 \\
\hline Setor III & 0,00 & 0,00 & 0,00 & 0,00 & 0,00 \\
\hline Setor IV & 0,01 & 0,02 & 0,10 & 0,01 & 0,00 \\
\hline Setor V & 0,00 & 0,00 & 0,00 & 0,00 & 0,10 \\
\hline Coef. de trabalho & 0,10 & 0,15 & 0,05 & 0,02 & 0,05 \\
\hline
\end{tabular}

Fonte: dados hipotéticos.

O Quadro 2 traz os resultados da aplicação das fórmulas acima aos dados do Quadro 1. Mostra, portanto, claramente o erro da tese marxista de que a soma dos valores iguala-se à soma dos preços de produção, pois não há desvios positivos que, devidamente ponderados, possam contrabalançar os negativos, de forma que qualquer que seja a ponderação, a soma dos preços será menor do que a soma dos valores.

Quadro 2

Valores e preços de produção

Em $£$ de ouro por unidade produzida

\begin{tabular}{|l|c|c|c|c|c|c|}
\hline Setores & $\begin{array}{c}\text { Capital } \\
\text { constante }\end{array}$ & $\begin{array}{c}\text { Capital } \\
\text { variável }\end{array}$ & $\begin{array}{c}\text { Preço de } \\
\text { custo }\end{array}$ & Mais-valia & Valor & Taxa de lucro \\
\hline Setor I & 1,549 & 2,339 & 3,888 & 0,886 & 4,775 & 0,228 \\
\hline Setor II & 0,471 & 3,509 & 3,980 & 1,329 & 5,309 & 0,334 \\
\hline Setor III & 0,726 & 1,170 & 1,896 & 0,443 & 2,339 & 0,234 \\
\hline Setor IV & 0,355 & 0,468 & 0,823 & 0,177 & 1,000 & 0,215 \\
\hline Setor V & 0,344 & 1,170 & 1,514 & 0,443 & 1,957 & 0,293 \\
\hline Setores & Custos & Salários & $\begin{array}{c}\text { Preço de } \\
\text { custo }\end{array}$ & Lucros & Preço & Desvios \\
\hline Setor I & 1,449 & 2,282 & 3,731 & 0,947 & 4,679 & $-0,096$ \\
\hline Setor II & 0,448 & 3,424 & 3,872 & 0,983 & 4,855 & $-0,454$ \\
\hline Setor III & 0,679 & 1,141 & 1,820 & 0,462 & 2,282 & $-0,057$ \\
\hline Setor IV & 0,341 & 0,456 & 0,798 & 0,202 & 1,000 & 0,000 \\
\hline Setor V & 0,326 & 1,141 & 1,467 & 0,373 & 1,840 & $-0,117$ \\
\hline Taxa de lucro(\%): 25,29 & & & & & \\
\hline
\end{tabular}

Como consequência, não é difícil concluir que tampouco o montante da mais-valia corresponde ao total dos lucros e muito menos que a taxa de lucro é a mesma nos dois sistemas, até porque, ao contrário do que ocorre no sistema de valores, onde a taxa média de lucro depende da quantidade produzida nos diversos 
setores, a determinação da taxa de lucro se dá sem qualquer ponderação em termos das quantidades produzidas. Finalmente, pode-se constatar, através da eliminação do setor $\mathrm{V}$ do referido quadro, que o mesmo, não obstante ser produtor de maisvalia, é irrelevante para a determinação tanto da taxa de lucro quanto dos preços dos demais setores.

\section{Determinando-se a taxa de lucro e os preços de produção pela lei do valor}

Embora as inconsistências identificadas na seção 1 sejam comumente apresentadas como argumentos definitivos contra a formulação marxista, cabe recolocar que a verdadeira questão é, conforme ressalta Engels (Marx, 1994, livro III, v. IV, p. 10), mostrar "como se pode formar e necessariamente se forma igual taxa média de lucro, sem ferir a lei do valor, mas, ao contrário, fundamentando-se nela", ou seja, demonstrar como os preços de produção se fundamentam no valortrabalho, ${ }^{15}$ revelando as mediações entre valores e preços de produção. "O problema da transformação consiste (...) em explicitar como a essência do capitalismo, captada através da categoria valor, governa a realidade efetiva dos preços de produção, que prevalecem na superfície fenomênica dessa sociedade" (Gontijo, 1989, p. 88), ${ }^{16}$ completando-se, assim, o processo de explicação da realidade efetiva iniciada através do estudo da mercadoria. Somente após ter sido resolvido satisfatoriamente esse problema, para o bem ou para o mal, é que se pode examinar a natureza e as consequências dos possíveis "erros" de Marx.

A possibilidade de se determinar a taxa de lucro a partir do sistema de valores é facilmente demonstrada. De fato, manipulando-se a equação vetorial de preços de produção e considerando-se que, em razão da produtividade da economia, a matriz $[\mathbf{I}-(1+\mathrm{r}) \mathbf{A}]$ é não singular, tem-se:

$$
\mathbf{p}=(1+\mathrm{r}) \mathrm{W} \mathbf{a}_{\mathbf{0}}[\mathbf{I}-(1+\mathrm{r}) \mathbf{A}]^{-1}
$$

Multiplicando-se, então, ambos os lados da identidade acima pelo vetor coluna representando a cesta de reprodução dos trabalhadores, $\mathbf{d}$, e levando-se em conta (1), (3) e (8), conclui-se que:

(15) Segundo Dobb (1955, p. 273), o problema da transformação "reside essencialmente em saber se os preços de produção (...) são dedutíveis do (...) valor, como determinado pelas quantidades de trabalho incorporado". Nesse sentido, somente seria correto afirmar que "Marx estava ciente de que os preços não deviam ser deduzidos dos valores" (Belluzzo, 1980, p. 114), se por dedução se entender uma derivação direta, diversa, portanto, daquela que se demonstra nesse artigo.

(16) Conforme sustenta Belluzzo (1980, p.112), "a tarefa que se impõe aos herdeiros da tradição marxista é a de demonstrar de que maneira a permanência da lei do valor em sua forma capitalista implica uma alteração permanente na expressão fenomênica do valor, vale dizer, no valor de troca". Não se pode concordar, por outro lado, com Tavares (1978, p. 46-47), que concebe a passagem de valores e preços como um mero "exercício lógico para demonstrar como se distribui o capital nas várias órbitas e como se consegue chegar ao conceito de taxa média de lucro". No entanto, conforme salientado na Introdução, não se discute nesse artigo o estatuto epistemológico da transformação. 


$$
\begin{aligned}
& 1=(1+r) \phi_{0} \mathbf{v}[\mathbf{I}-\mathbf{A}][\mathbf{I}-(1+r) \mathbf{A}]^{-1} \mathbf{d}= \\
& =\boldsymbol{\phi}[\mathbf{I}-\mathbf{A}]\left[(1+\mathrm{r}) \mathbf{I}+(1+r)^{2} \mathbf{A}+(1+r)^{3} \mathbf{A}^{2}+\ldots\right] \mathbf{d}
\end{aligned}
$$

A equação (17), que não faz qualquer referência aos preços de produção, confirma que o sistema tradicional de valores é suficiente para se determinar a taxa de lucro, que, conforme se verifica, depende do trabalho social incorporado nas diversas mercadorias $(\boldsymbol{\phi})$, do salário real $(\mathbf{d})$ e da tecnologia de produção $(\mathbf{A})$. Ressalte-se que, uma vez obtida a taxa de lucro, basta substituir o seu valor em (10) para que se determine univocamente o vetor de preços de produção.

\section{A necessidade da lei do valor}

A demonstração da possibilidade de se determinar tanto a taxa de lucro quanto os preços de produção, "sem ferir a lei do valor, mas, ao contrário, fundamentando-se nela", não é nova, estando implícita na formulação sraffiana das quantidades datadas de trabalho (Sraffa, 1960, p. 241-244). Ao contrário de Napoleoni (1977, p. 98), que, sem qualquer justificativa, interpreta (17) como uma "teoria burguesa" em que "o trabalho é um fator entre outros", o próprio Steedman a reconhece, embora procure desmerecê-la, na medida em que afirma que "a análise do trabalho datado representa nada mais do que uma forma de reescrever a análise das quantidades físicas" (Steedman, 1977, p. 73).

Por "quantidades físicas", entende Steedman as equações sraffianas, que se baseiam exclusivamente nos coeficientes técnicos de produção e na cesta de reprodução dos trabalhadores. Mais do que isso, na medida em que a taxa de lucro difere do quociente entre a mais-valia total e o valor do capital total e depende "somente da cesta de consumo dos trabalhadores e das condições (diretas e indiretas) de sua produção", não sendo, portanto, função "das condições de produção dos 'bens de luxo' ou de qualquer meio de produção usado exclusivamente na produção dos mesmos" (Steedman, 1977, p. 73), conclui-se que é forçoso fundamentar a teoria dos lucros e preços exclusivamente nas condições físicas (técnicas) de produção e no salário real, com o descarte da lei do valor (Steedman, 1977, p. 48).

A contestação dessa crítica e, portanto, a demonstração da necessidade da teoria do valor-trabalho, pode ser feita a partir de pelo menos cinco argumentos. $\mathrm{O}$ primeiro diz respeito ao caráter axiomático da mesma, identificado claramente por Rubin (1928, p. 116), que salienta que, enquanto toda sociedade mais avançada "supõe necessariamente certa distribuição do trabalho social entre os diversos ramos da produção", na sociedade capitalista "ninguém controla a distribuição do

trabalho entre os ramos particulares da produção e entre as empresas particulares". Dessa forma, faz-se necessária uma lei impessoal que, impondo-se sobre os 
produtores particulares, distribua de forma adequada o trabalho social. ${ }^{17}$ Nessa perspectiva, qualquer ciência da sociedade deve demonstrar a forma pela qual o trabalho social regula uma sociedade mercantil, ou seja, há de se construir uma teoria necessariamente baseada no valor-trabalho.

$\mathrm{O}$ segundo argumento, associado ao primeiro, reconhece que a teoria do valor-trabalho permite identificar qual é o custo de cada uma das mercadorias, assim como do conjunto das mesmas, para a sociedade como um todo e para os trabalhadores, e não apenas para os capitalistas. Enquanto para estes os custos são dados pelos dispêndios de capital, tanto para os trabalhadores quanto para a sociedade como um todo, os custos estão constituídos pela quantidade de trabalho social despendido na produção. A lei do valor dá conta desse duplo aspecto da produção no capitalismo, que simultaneamente representa alocação do trabalho social - aspecto comum em todas as ordens econômicas - e alocação de dinheiro para fins de valorização. Abandonar, pois, a teoria do valor-trabalho em favor de uma teoria restrita aos preços de produção significa renunciar à compreensão do nexo necessário entre essas duas dimensões da produção na sociedade capitalista.

O terceiro argumento é de natureza metodológica e reside no caráter sistemático da ciência, que não pode admitir hipóteses não demonstradas, que brotam necessariamente tão logo se abandone a lei do valor. ${ }^{18}$ Conforme discutido na seção 1, $O$ Capital se fundamenta no desdobramento das categorias da mercadoria, concebida como universal concreto, ou seja, como a categoria geral que resume, como germens não desenvolvidos, todas as determinações e relações que compõem a totalidade do capitalismo, que nada mais representa do que a explicitação da lógica contida na mercadoria. ${ }^{19}$

É a partir dessa lógica que se explica, por exemplo, a gênese e as funções do dinheiro, assim como o processo de acumulação de capitais e a concorrência entre os capitalistas. Conforme demonstra Marx, a própria circulação mercantil gera necessariamente o afã de acumular mais dinheiro, de forma que o dinheiro se transforma em finalidade da circulação mercantil, gerando, assim, um processo sem fim (ou seja, cuja finalidade está em si mesma) de acumulação de capital. Com a emergência histórica do trabalho assalariado, esse processo passa a produzir suas próprias condições de existência, desenvolvendo-se o modo de produção capitalista.

Ao se prescindir da lei do valor, torna-se necessário fazer toda uma série de hipóteses, a começar sobre a natureza e as funções do dinheiro e o desejo de

(17) Essa distribuição se faz comandada pelos preços de produção, que, nas palavras de Belluzzo (1980, p. 113), "exprimem uma relação de equivalência entre os capitais". E, conforme salienta Rubin (1928, p. 280), "na sociedade capitalista, a distribuição do trabalho está regulada pela distribuição de capital".

(18) Para uma discussão do método da economia clássica, ver Gontijo (1999).

(19) A esse respeito, ver, além de Gontijo (1989, 2000), Rosdolsky (1968) e Zelený (1968). 
acumular dos empresários, para não falar sobre o comportamento das empresas, que, por hipótese inteiramente graciosa, se transformam em instituições maximizadoras de lucro. Em contraposição, ao se utilizar a teoria do valortrabalho, explicam-se as raízes do processo de concorrência intercapitalista, sem a necessidade de qualquer hipótese não demonstrada sobre o comportamento dos empresários. Enfim, é somente por desprezar o método lógico-dedutivo que Samuelson, Napoleoni e Steedman propõem o abandono do princípio unificador da economia clássica - a lei do valor-trabalho - em favor de teorias que representam verdadeiras colchas de retalho, costuradas a partir de hipóteses não demonstradas.

O quarto argumento reconhece que a proposta de se obter a taxa de lucro e os preços diretamente dos "coeficientes técnicos de produção" e do salário real, ou seja, utilizando-se das identidades (8), (9) e (10), equivale, na prática, a escamotear sumariamente o conteúdo social incorporado nessas variáveis, a começar pela exploração do trabalho. É como se a duração da jornada e a intensidade do trabalho, para não falar no salário real, fossem aspectos tecnológicos, "não sociais" e independentes tanto da ordem de produção existente quanto da correlação de forças entre as classes sociais próprias dessa ordem. ${ }^{20} \mathrm{Em}$ outras palavras, implica descartar o modo concreto pelo qual a luta de classes emerge no processo produtivo capitalista.

Conforme assinala Marx (1863, livro I, cap. XIV, p. 596),

as magnitudes relativas do preço da força de trabalho ${ }^{21}$ e da mais-valia [ - ou seja, a taxa de mais valia -] são determinadas por três circunstâncias: 1) a duração do trabalho ou a magnitude extensiva do trabalho; 2) a intensidade normal do trabalho ou sua magnitude intensiva, segundo a qual dada quantidade de trabalho é despendida em determinado espaço de tempo; 3) finalmente, a produtividade do trabalho, segundo a qual a mesma quantidade de trabalho fornece no mesmo tempo uma quantidade maior ou menor de produto, dependendo do grau de desenvolvimento das condições de produção.

Contudo, as variáveis duração da jornada de trabalho $(\eta)$ e intensidade do trabalho $(\psi)$ foram omitidas no desenvolvimento analítico realizado na seção 1 , que segue a abordagem tradicional (e a crítica ao marxismo) dos neorricardianos.

Para incorporá-las à análise, é necessário considerar, em primeiro lugar, que as identidades que definem o valor (e o preço) da força de trabalho se baseiam

(20) Napoleoni (1977, p. 97) incorre nesse erro, ao postular que, no processo de determinação dos preços, "o trabalho é obviamente um trabalho tecnicamente e não socialmente determinado". Napoleoni vai ainda mais longe quando afirma que, nesse processo, "o valor-trabalho é medido numa relação matemática com o preço, e nesta relação ele torna-se necessariamente uma realidade técnico-natural, passando a fazer parte, como um elemento entre outros, do mundo físico das coisas e dos produtos". Essas afirmativas soam como se o autor tivesse caído sob os efeitos do fetiche da mercadoria.

(21) Marx refere-se ao valor da força de trabalho, em lugar de seu preço. 
na cesta de bens e serviços necessários para a reprodução da mesma durante determinado período de tempo (um mês, por exemplo). Os coeficientes de trabalho representam as quantidades de trabalho direto requerido para se produzir uma unidade dos diferentes bens e serviços, e que podem estar expressas em diferentes medidas de tempo (horas ou dias de trabalho, por exemplo).

Obviamente que, para tornar o modelo consistente, as unidades de medidas de tempo têm de ser compatibilizadas. Assim, por exemplo, se a cesta de consumo dos trabalhadores refere-se aos requerimentos anuais de reprodução da mesma, os coeficientes de trabalho devem estar expressos em termos da quantidade média de trabalho executada por uma pessoa por um ano e não em horas ou dias de trabalho. Ocorre, porém, que, em segundo lugar, ao se prolongar (reduzir) a jornada de trabalho ou ao se aumentar (reduzir) sua intensidade, caem (aumentam) os coeficientes técnicos de produção expressos em termos da quantidade média de trabalho executada por uma pessoa por um ano (ou em dias ou semanas), embora os requerimentos de trabalho de intensidade "normal", medidos em horas de trabalho, permaneçam os mesmos.

Para se identificar, então, os efeitos das variações da produtividade, duração da jornada e intensidade do trabalho, assumindo-se que a cesta de reprodução dos trabalhadores, $\mathbf{d}$, corresponde aos requerimentos anuais em termos de bens e serviços, considera-se que os coeficientes técnicos de trabalho, medidos em termos da quantidade média de trabalho executada por uma pessoa por um ano são iguais a:

$$
\mathbf{a}_{\mathbf{0}}=\mathbf{u} / \eta \psi
$$

onde u significa o vetor-linha dos coeficientes de trabalho de dada intensidade, expresso em horas de trabalho, como o inverso da produtividade do trabalho direto gasto na produção de cada uma das mercadorias. ${ }^{22}$

Substituindo-se, então, a identidade (18) em (2) e considerando-se (7), obtém-se:

$$
\varepsilon=\eta \psi / \mathbf{u}[\mathbf{I}-\mathbf{A}]^{-1} \mathbf{d}-1
$$

o que demonstra claramente que, assumindo-se dada produtividade do trabalho, a taxa de mais-valia é diretamente proporcional tanto em relação à duração da jornada quanto à intensidade do trabalho.

A Figura 1 mostra a relação entre a taxa de mais-valia e a duração da jornada de trabalho, supondo diferentes níveis de intensidade do mesmo (assumiuse a intensidade "normal" como igual à unidade), utilizando-se os dados do Quadro 1, considerando-se 240 dias úteis por ano.

(22) Alternativamente, pode-se redefinir o valor e o preço da força de trabalho, substituindo as identidades (5) e (8) por $\omega=\mathbf{v} \mathbf{d} / \eta \psi$ e $w=\mathbf{p} \mathbf{d} / v \psi$, respectivamente. 
Figura 1

Relação entre tempo e intensidade do trabalho e a taxa de mais-valia

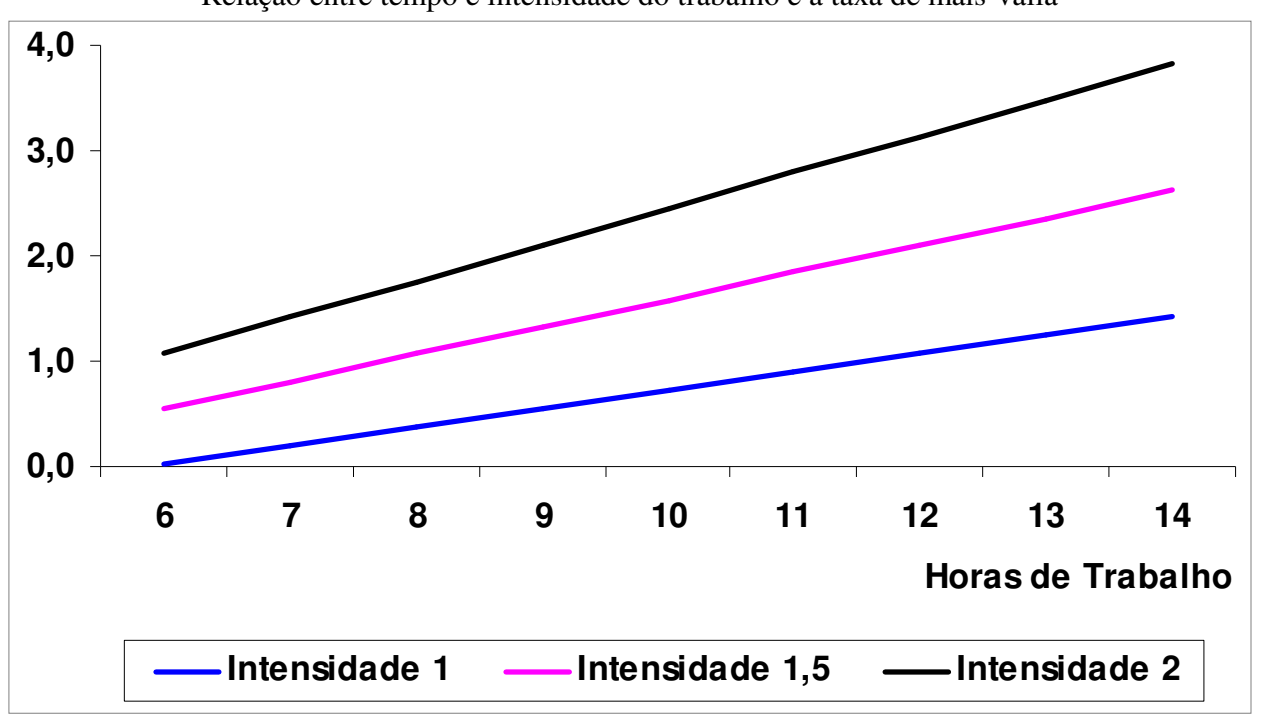

Uma vez identificada a relação entre a duração da jornada de trabalho e a intensidade do mesmo sobre a taxa de mais-valia, torna-se possível determinar a relação entre esta última variável e a taxa de lucro. Assim, multiplicando-se (16) pela cesta de reprodução dos trabalhadores, d, e tomando-se em conta (8), (16) e (17), conclui-se que:

$$
1=\frac{(1+r) u[I-(1+r) A]-1 d}{(1+e) u[I-A]-1 d}
$$

A identidade (20) demonstra não só que o sistema tradicional de valores é suficiente para se determinar a taxa de lucro, que é função da tecnologia de produção (A), dos coeficientes de trabalho, expressos em horas de trabalho (u), do salário real (d) e da taxa de mais-valia $(\varepsilon)$, mas que a taxa de lucro varia diretamente com a taxa de mais-valia. Assim, uma elevação de $\varepsilon$ - resultante, por exemplo, do aumento da jornada de trabalho, mantendo-se todas as outras variáveis constantes - faz aumentar o denominador, requerendo-se um aumento correspondente do numerador para se manter a unidade, o que significa a elevação da taxa de lucro, $\mathrm{r}^{23}$ Isso pode ser visto através da Figura 2, que retrata a relação entre taxa de mais-valia e taxa de lucro, assumindo-se os coeficientes técnicos do

(23) Note-se que a identidade (20) mostra que a taxa de mais-valia é maior do que a taxa de lucro. Também serve para demonstrar aquilo que Morishima e Catephres (1980, p. 173) denominaram "teorema marxista fundamental", que estabelece que "a condição necessária e suficiente para uma taxa de lucro de equilíbrio positiva é que a taxa de exploração seja positiva". 
Quadro 1, ou seja, supõe-se constantes tanto a jornada quanto a intensidade do trabalho.

Figura 2

Relação entre taxa de lucro e taxa de mais-valia

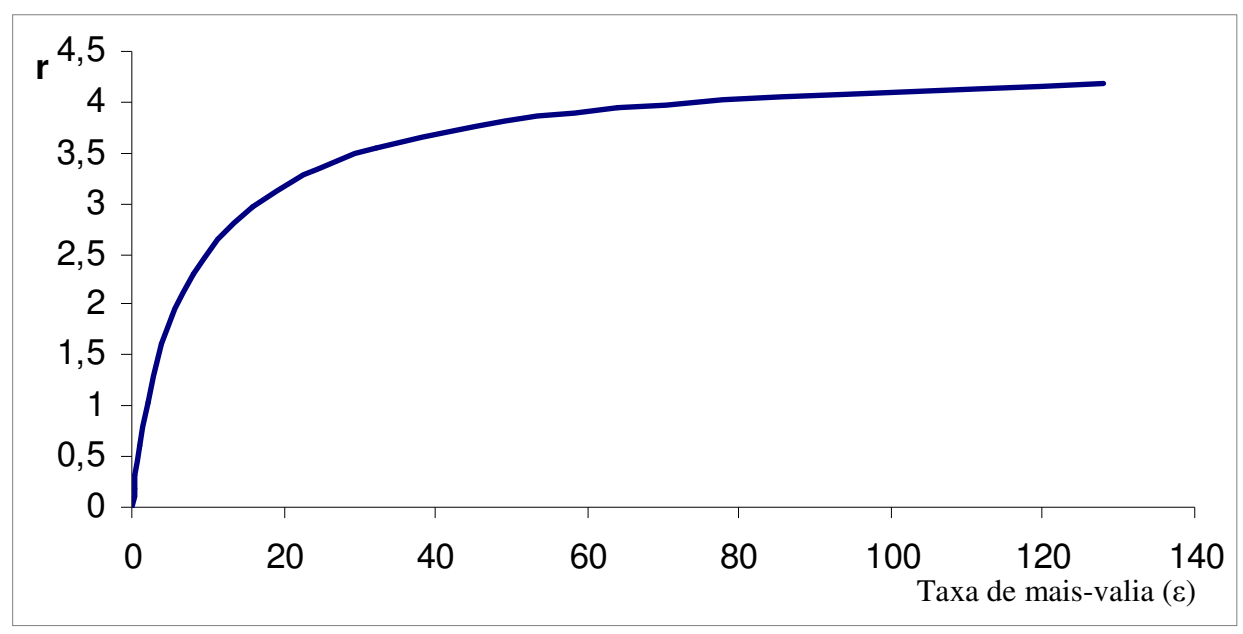

Em outras palavras, estando perfeitamente determinada ao nível do sistema de valores, a taxa de lucro é função da taxa de mais-valia (e, portanto, da duração da jornada e da intensidade do trabalho), o que não só confirma plenamente a análise de Marx desenvolvida no Livro I de $O$ Capital, ${ }^{24}$ mas revela o equívoco de se querer despir os coeficientes técnicos de produção de seu conteúdo social, explicitado pela análise do valor-trabalho.

Finalmente, a teoria do valor-trabalho permite não só derivar todas as categorias econômicas presentes na economia de mercado (preços de produção, que funcionam como centros de gravitação dos preços de mercado, salário, lucro e taxa de lucro, juro e taxa de juros, renda da terra, preço do solo e dos ativos financeiros, etc.), como muito bem demonstra Marx, dentro das limitações da matemática da época, mas também dá conta da economia mercantil simples.

Abandoná-la, seria, assim, renunciar a uma teoria geral das economias de mercado. Reservadas as respectivas proporções, seria o mesmo que pedir a Newton que construísse uma teoria da gravitação específica para a Terra, visto que os corpos que estão muito próximos à sua superfície não se comportam como os $\mathrm{s}$ que estão no espaço cósmico, onde não sofrem os efeitos do atrito do ar, em lugar

(24) "A mais-valia permanece como relação central, a partir da qual é construído o conceito de lucro, e de onde parte a possibilidade da formação de uma taxa média de lucro" (Belluzzo, 1980, p. 114). Não é sem motivo que "o conceito de taxa média de lucro, em Marx, não pode ser determinado apenas 'tecnicamente', nem muito menos através de um sistema de equações simultâneas de preços" (Idem, p. 116). 
de se verificar como a lei da gravitação universal é modificada pela presença da atmosfera terrestre.

\section{Sumário e Conclusões}

Da análise precedente conclui-se que, apesar dos erros de Marx, a lei do valor representa fundamento necessário para o sistema de preços de produção, visto que, em primeiro lugar, possui caráter axiomático, na medida em que, em toda sociedade mercantil, a distribuição do trabalho social tem de necessariamente se impor sobre os produtores independentes, que somente se articulam através do mercado. Além disso, ao contrário da teoria neorricardiana de preços de produção, a teoria do valor-trabalho permite dar conta do duplo caráter das mercadorias, que custam capital para os capitalistas, mas custam trabalho tanto para os trabalhadores quanto para a sociedade como um todo.

Em segundo lugar, é através da teoria do valor-trabalho que a economia se transforma em sistema científico, que não pode admitir hipóteses não demonstradas. Prescindir dela significa romper com o princípio da autofundamentação da ciência que, embora possa ser desdenhado por muitos economistas, particularmente por aqueles que têm pouca familiaridade com a epistemologia da ciência, está presente em $O$ Capital. Estabelecendo como ponto de partida a mercadoria tomada como imediato concreto, ou seja, como pressuposto dado, termina-se com a mercadoria como produto do capital (Marx, 1971, p. 109-137), fechando-se assim, o círculo da autodemonstração proposto por Hegel (1812), em sua magistral discussão do método. Significa abrir mão do princípio unificador da economia clássica em favor de teorias que mais se assemelham a mosaicos montados a partir de hipóteses graciosas, tais como a de que as empresas maximizam lucros e a de que os empresários acumulam capital.

Em terceiro lugar, a proposta de se obter a taxa de lucro e os preços diretamente dos "coeficientes técnicos de produção" e do salário real equivale, em termos concretos, a escamotear sumariamente o conteúdo social incorporado nessas variáveis, a começar pela exploração do trabalho. Aliás, a proposta neorricardiana, ao omitir a duração da jornada e a intensidade do trabalho, para não falar do conteúdo sociológico do salário real, que depende tanto da ordem de produção existente quanto da correlação de forças entre as classes sociais próprias dessa ordem, desconsidera a dependência funcional da taxa de lucro em relação à taxa de mais-valia. Descarta-se, assim, o modo concreto pelo qual a luta de classes emerge do processo produtivo capitalista, comprometendo definitivamente a compreensão adequada da sociedade moderna.

Finalmente, a teoria do valor-trabalho permite derivar sistematicamente todas as categorias econômicas da economia de mercado, dando conta, de mais a 
Cláudio Gontijo

mais, da economia mercantil simples, de modo que abandoná-la equivale a renunciar a uma teoria geral das economias de mercado.

\section{Referências bibliográficas}

BELLUZZO, L. G. de M. Valor e capitalismo. São Paulo: Brasiliense, 1980.

DOBB, M. A note on the transformation problem. In: ON ECONOMIC theory and socialism. Collected Papers. London: Routledge \& Kegan Paul, 1995.

ENGELS, F. (1894). Prefácio. In: MARX, K. O Capital. $1^{\text {st }}$ ed. . Rio de Janeiro: Civilização Brasileira, [s.d.]. Livro III, v. IV, p. 3-24.

FINE, B.; LAPAVITSAS, C.; SAAD-FILHO, A. Transforming the transformation problem: Why the 'new solution' is a wrong turning. Review of Radical Political Economics, v. 36, n. 1, p. 3-19, 2004.

GANSSMANN, H.. Transformation of physical conditions of production: Steedman's economic metaphysics. Economy \& Society, v. 10, n. 4, p. 403-422, 1981.

GLICK, M.; EHRBAR, H. The transformation problem: an obituary. Australian Economic Papers, n. 26, p. 294-317, Dec. 1987.

GONTIJO, C. A transformação de valores em preços segundo o Sistema Temporal Único: uma apreciação crítica. Revista EconomiA, v. 9, n. 1, p. 215-243, 2008.

A 'nova solução' do problema da transformação de valores em preços: uma apreciação crítica. Revista EconomiA, v. 7, n. 2, p. 225-248, 2006.

On the criticism to the classical method. Revista Brasileira de Economia, v. 54, n. 1, p. 85-122, 2000.

. A epistemologia da transformação - Uma crítica ao neo-ricardianismo. Revista de Economia Política, v. 9, n. 3, p. 84-102, 1989.

GRAHAM, A. Non-negative matrices and applicable topics in linear algebra. New York: John Wiley, 1987.

HEGEL, G. W. F. (1812). Ciencia de la lógica. $1^{\text {st }}$ ed. Buenos Aires: Solar-Hachette, 1968.

MARX., K. (1859). Para a crítica da economia política. $1^{\text {st }}$ ed. São Paulo: Victor Civita, 1982.

- Elementos fundamentales para la crítica de la economia política (Borrador)

1857-1858. Buenos Aires: Siglo Veintiuno, 1971. 3v.

Economic manuscripts of 1861-1863. In: MARX. K.; ENGELS, F. Collected Works. New York: International Publishers, 1988. v. 30.

O Capital. Rio de Janeiro: Civilização Brasileira, [s.d.]. (1867-1894, 6 v.)

1971.

- El Capital, Livro I, Capítulo VI (Inédito). Buenos Aires: Siglo Veintiuno, 
MONGIOVI, G. Vulgar economy in Marxian garb: a critique of temporal single system Marxism. Review of Radical Political Economics, 32, p. 393-416, 2002.

MONZA, A. Sraffa e sus usos. Cidade de México, 1979. Mimeografado.

MORISHIMA, M.; CATEPHORES, G. (1978). O problema de transformação: um processo de Markov. In: VALOR, exploração e crescimento. $1^{\text {st }}$ ed. Rio de Janeiro: Zahar, 1980. p. 163-195.

NAPOLEONI, C. O valor na ciência econômica. Lisboa: Presença, 1977.

RAVAGNANI, F. A critical note on Moseley's 'macro-monetary' interpretation of Marx's Theory. Review of Radical Political Economics, v. 37, n. 1, p. 85-96, 2005.

ROSDOLSKY, R. (1968). Génesis y estructura de El Capital de Marx. $1^{\text {st }}$ ed. Cidade do México: Siglo Veintiuno, 1978.

RUBIN, I. (1928). Ensayos sobre la teoria marxista del valor. 1. ed. Buenos Aires: Ed. Siglo Veintiuno, 1974. (Cuadernos P\&P).

SAMUELSON, P. Wages and interest: a modern dissection of Marxian economic models. American Economic Review, v. 47, p. 884-912, 1957.

Understanding the Marxian notion of exploitation: a summary of the so-called transformation problem between Marxian values and competitive prices. Journal of Economic Literature, v. 9, n. 2, p. 399-431, 1971.

Insight and detour in the theory of exploitation: A reply to Baumol. Journal of Economic Literature, v. 12, n. 1, p. 62-70, 1974.

SINHA, A. The transformation problem: a critique of the 'New Solution'. Review of Radical Political Economics, v. 29, n. 3, p. 51-58, 1997.

SRAFFA, P. (1960). Produção de mercadorias por meio de mercadorias. In: KEYNES, J. M. et al. Ensaios econômicos. 1. ed.. São Paulo: Victor Civita, 1976. p. 209-290.

STEEDMAN, I. Marx after Sraffa. Thetford: New Left Books, 1978.

TAVARES, M. da C. Ciclo e crise. Tese (Concurso para Professor Titular)-Universidade Federal do Rio de Janeiro, 1978. Rio de Janeiro. Mimeografado.

ZELENÝ, J. (1968). The logic of Marx. $1^{\text {st }}$ ed. Totowa: Rowman and Littlefield, 1980. 